\title{
Kültüre Duyarlı Psikolojik Danışma Yeterliklerinin Yordanmasında Kültürel Zekâ, Çok Kültürlü Psikolojik Danışma Eğitimi ve Mesleki Deneyimin Rolü
}

\author{
Oğuzhan Yıldırım (Dok. Öğr.) \\ Ondokuz Mayıs Üniversitesi-Türkiye \\ oguzhanyildirim.pdr@gmail.com
}

\begin{abstract}
Özet:
Bu araştırmanın amacı psikolojik danışmanların kültürel zekâ, çok kültürlü psikolojik danışma eğitimi ve mesleki deneyimlerinin kültüre duyarlı danışma yeterliklerini ne düzeyde yordadığını incelemektir. Tarama modelinin kullanıldığı bu araştırma aktif çalışan 115 psikolojik danışman ile yürütülmüştür. Araştırmanın verileri "Çok Kültürlü Psikolojik Danışma Yeterlikleri Ölçeği" ve "Kültürel Zekâ Ölçeği" ile toplanmıştır. Ölçeklerden elde edilen verilerin analizinde Pearson momentler çarpımı korelasyon katsayısı hesaplanmış ve çoklu doğrusal regresyon analizi yapılmıştır. Araştırma sonuçlarına göre kültürel zekâ, çok kültürlü psikolojik danışma eğitimi ve mesleki deneyim ile kültüre duyarı danışma yeterlikleri arasında anlamlı ilişkilerin olduğu görülürken yordayıcı değişkenlerin birlikte yordanan değişkendeki değişimin \%34'ünü açıkladığı tespit edilmiştir. Regresyon katsayılarının anlamlılık testlerine göre sadece kültürel zekânın kültüre duyarlı danışma yeterliklerini yordadığı belirlenmiştir.
\end{abstract}

Keywords: Kültüre duyarlı psikolojik danışma yeterlikleri, Kültürel zekâ, Çok kültürlü danışma eğitimi, Mesleki deneyim

DOI: 10.19160/ijer.676897

E-Uluslararası Eğitim Araşturmaları Dergisi, Cilt: 11, Sayt: 1, 2020, ss. 41-52

\section{Önerilen Atıf}

Yıldıım, O. (2020). Kültüre Duyarlı Psikolojik Danışma Yeterliklerinin Yordanmasında Kültürel Zekâ, Çok Kültürlü Psikolojik Danışma Eğitimi ve Mesleki Deneyimin Rolü. E-Uluslararası Eğitim Araştırmaları Dergisi, Cilt: 11, Sayı: 1, 2020, ss. 41-52, DOI: 10.19160/ijer.676897 


\section{GiRiş}

Psikolojik danışmanlık; insanların kişisel, sosyal, kariyer ve akademik yaşantılarında yeterli olmasına yardımcı olan ve bu alanlarda yaşadıkları problemleri çözmeleri için destek sağlayan bir ruh sağlığı mesleğidir (Yüksel-Şahin, 2018). Yalnızca etkili psikolojik danışmanlık becerilerine sahip olan danışmanlar yürüttükleri psikolojik danışma sürecini etkili ve verimli kılabilirler. Bu konuda danışmanların kişilerarası ilişkilerde ve teknik becerilerde başarıı olması gereklidir (Charkuff, 2011). Psikolojik danışmanlar yeterliklerini geliştirmeleri için bazı özelliklere sahip olmalıdırlar. Bu özelliklere sahip olan danışmanlar kendilerini iyi tanıyan, değiş̧ime açık, özsaygısı olan, otantik ve dürüst davranan, hatasını kabul edebilen, mizahi bir anlayışa sahip ve kültürün danışma sürecindeki etkisinin farkında olan danışmanlardır (Corey, 2008). Bunların dışında empatik anlayışa sahip, yardım etme konusunda gönüllü, öz farkındalık düzeyi yüksek ve iletişime açık olan danışmanlar danışmanlık yeterliklerine sahiptirler (Korkut-Owen, Tuzgöl-Dost ve Bugay, 2014).

Psikolojik danışma sürecindeki en önemli iki bileşen danışman ile danışandır. Danışma sürecinin etkililiğini belirleyen danışana (kişilik özelliği, sosyal destek, ruh sağlığı, motivasyon) ve danışmana (yeterlik, kişilik özelliği, alınan eğitimler) ait birçok faktör bulunmaktadır. Bu faktörlerin yanında kültürel özellikler de oldukça önemli bir yere sahiptir (Kağnıcı, 2013). Psikolojik danışmanlar kendi kültürlerine ait özelliklerini danışma ortamına getirebilirler. Bu nedenle kültürel özelliklerinin terapi sürecini nasıl etkilediği konusunda farkındalık sahibi olmalı ve dikkatli davranmalıdırlar (Corey, 2008). Kültür yalnızca ırk ve etnik köken gibi olguları barındırmamaktadır. Kültüre dair birçok kavram, kültüre duyarlı psikolojik danışma sürecinde dikkate alınır. Cinsiyet (Sue, 2001), cinsel yönelim (Davis, 2014), dini anlayış (Whitman ve Bidell, 2014) ve sosyoekonomik durum (Corey, 2008) da kültüre duyarlı psikolojik danışma konuları içinde yer alır. Kültüre duyarlı danışma yeterliğine sahip danışmanlar öncelikle kendileri ve kendi kültürleri hakkında farkındalık sahibidirler. Bu danışmanlar sahip olunan düşüncelerin ve edinilen tecrübelerin dünya görüşünü oluşturmadaki rolünün de farkındadırlar. Bu yeterliğe sahip danışmanlar danışanlarının deneyim ve düşüncelerinin farkında olarak danışanların davranışlarını ve sorunlarını belirleyen etmenleri daha net görebilirler (Sue, 2001).

Danışanlar profesyonel destek almaya karar vermeden önce bazı engellerle karşılaşırlar. Bu engelleri bir şekilde aşabilen kişiler psikolojik danışma sürecine dâhil olurlar. Özellikle kültürel faktörlerin neden olduğu sorunlar yaşayan kişilerin kültüre duyarlı danışma yeterliğine sahip danışmanlarla görüşmek istemeleri kaçınılmazdır. Örneğin farklı cinsel yönelimi olan ve bunu gizlemek zorunda hisseden bir yetişkin, büyük erkek kardeşi öldükten sonra erkek kardeşinin dul kalan eşi ile evlendirilen bir genç, mezhepsel farklııklardan ötürü birlikte olamayan çiftler kültürel empati becerisine sahip bir danışman bulmak isterler (Kağnıcı, 2013).

Bir arada yaşayan insanların tamamen aynı davranmaları ve daima ortak özelliklere sahip olmaları beklenemez. Aynı toplumda yaşayan insanlar bile kişilik özellikleri, yaşam biçimleri, aile yaşantıları ve ekonomik durumları bakımından farklı özelliklere sahiptirler. Bektaş'a (2006) göre kişiler arasındaki farklılıkların en büyük nedenlerinden biri içinde bulundukları kültürdür. Kültür; yaşanan coğrafi bölgeyi, dini inanışı, içinde bulunulan ulusun niteliklerini ve etnik kökeni kapsar. Çok kültürlülük ise çeşitli kültürlerin bir arada olması anlamına gelir (Çelik, 2008). Yakışır'a (2008) göre çok kültürlülük insan yaşamında politik ve kültürel sorunlardan biri haline gelebilmektedir. Kişiler arasında görülen yaş ve sosyoekonomik durum gibi farklılıkların yanında etnik köken ve değer yargıları gibi kültürden kaynaklanan farklııklar da bulunmaktadır. Bu farklılıklar kültürden kaynaklanan problemlerin nedeni olabilmektedir. Bu bağlamda psikolojik danışmanların verimli ve etkili danışma hizmeti verebilmeleri için kültüre duyarlı psikolojik danışma yeterliğine sahip olmaları gerekmektedir (Demir, 2016). 
Psikolojik danışma kuramlarl; içinde geliştiği toplumun düşünce biçimini ve kültürel değerlerini yansıtmaktadır. Ancak her toplumun farklı normlara, alışkanlıklara, ödül ve ceza yöntemlerine ve metaforlara sahip olduğu düşünüldüğünde farklı kültüre duyarlı psikolojik danışma sürecinin önemi ortaya çıkmaktadır (Erdur-Baker, 2007). Kültüre duyarlı yeterlik ile ilişkili olan kültürel zekâ kavramı; farklı kültürlere adapte olabilme, bu kültürlerdeki kişilerle iletişim kurabilme ve içinde bulunulan kültürle uyumlu davranışlar sergileyebilme becerisi olarak ifade edilmektedir (Early ve Ang, 2003). Kültürel zekâ stratejilerini kullanan psikolojik danışmanların kültüre duyarlı danışma yeterliklerinin daha yüksek olduğu görülmektedir (Leong ve Lee, 2016). Illk olarak ABD'de ortaya çıkan ve önemi 1960 'ı yıllarda anlaşılmaya başlanan kültüre duyarlı psikolojik danışmada en önemli konulardan biri çok kültürlü psikolojik danışman eğitimi olmuştur (Kağnıcı, 2013). Danışmanlık yeterliklerini belirleyen psikolojik danışmanlık eğitimlerinin içeriğinde kültürlerarası duyarlığa yönelik eğitimlerin önemli bir yeri vardır (Aydın, 2014). Ayrıca mesleki deneyimleri yüksek olan psikolojik danışmanların daha fazla danışma süreci geçirdiği ve dolayısıyla farklı kültürlerden danışanlarla daha çok çalıştığı düşünülmektedir. Tüm bunlar dikkate alındığında kültüre duyarlı psikolojik danışma yeterliği ile kültürel zekâ, çok kültürlü psikolojik danışma eğitimi ve mesleki deneyimin bir arada çalışıımasının önemli olduğu görülmektedir.

Bu araştırmada "Psikolojik danışmanların kültüre duyarlı psikolojik danışma yeterliklerini kültürel zekâ, çok kültürlü psikolojik danışma eğitimi ve mesleki deneyimleri ne düzeyde yordamaktadır?" sorusuna yanıt aranmıştır.

\section{YÖNTEM}

$\mathrm{Bu}$ araştırmada nicel araştırma yöntemlerinden ilişkisel tarama modeli kullanılmıştır. Can'a (2017) göre bu modelde en az iki değişkene ait veriler toplanır ve değişkenler arasındaki ilişkinin incelenmesi amaçlanır. Araştırmanın bağımlı değişkenini kültüre duyarlı psikolojik danışma yeterlikleri; bağımsız değişkenlerini ise kültürel zekâ, çok kültürlü psikolojik danışma eğitimi ve mesleki deneyimler oluşturmuştur.

\section{Çalışma Grubu}

Çoklu regresyon analizinin yapıldığı araştırmalarda belirlenecek örneklem sayısı konusunda farklı görüşler bulunmaktadır. Bu araştırmanın örneklem sayısı ise farklı görüşlerin incelenmesiyle belirlenmiştir. Tabachnick ve Fidell (2015) örneklem sayısını hesaplarken N > $50+$ $8 m$ ( $m$ =bağımsız değişken sayısı) formülünün kullanılmasını önermiştir. Başka bir görüşe göre çoklu regresyon işlemleri için bağımsız değişken sayısının beş katı olacak kadar bir örneklem sayısı yeterli olacaktır (Cohen ve Cohen, 1983; Akt., Can, 2017, s.276). Bu araştırmada Türkiye'nin yedi coğrafi bölgesinde görev yapan yaşları 22 ile 50 arasında değişen115 psikolojik danışmandan veri toplanmıştır. Katılımcıların 6 'sı anaokulunda, 15'i ilkokulda, 47'si ortaokulda ve 45'i lisede görev yapmaktadır. 31'i İç Anadolu Bölgesi'nde, 23'ü Karadeniz Bölgesi'nde, 22'si Marmara Bölgesi'nde, 11'i Akdeniz Bölgesi'nde, 9'u Doğu Anadolu Bölgesi'nde, 11'i Ege Bölgesi'nde, 6'sı Güneydoğu Anadolu Bölgesi'nde çalışmaktadır. Psikolojik danışmanların 87'si lisans mezunu iken 26 'sı lisansüstü eğitimi almıştır. Katılımcılar rastgele olmayan amaçlı örnekleme yöntemiyle seçilmişlerdir. Amaçlı örnekleme yönteminde katılımcılar, evrenin özelliklerine sahip olanlar arasından seçilir (Johnson ve Christensen, 2014, s.231). Bu araştırmada katılımcıların aktif şekilde görev yapan psikolojik danışmanlardan oluşması amaçlanmıştır.

\section{Veri Toplama Araçları}

Çok Kültürlü Psikolojik Danışma Yeterlikleri Ölçeği: Özer tarafından 2014 yılında geliştirilen ölçek 5'li Likert tipindeki 26 maddeden oluşur. Ölçekten alınan yüksek puanlar kültüre duyarlı psikolojik danışma yeterlik düzeyinin yüksek olduğu anlamına gelir. Ölçekten alınabilecek 
puanların 26-130 arasında değişmektedir ve dokuz maddesi $(2,4,7,10,12,15,17,19,24)$ ters puanlanmaktadır. Ölçeğin güvenirlik çalışmasını yapmak amacıyla Cronbach Alfa katsayıları hesaplanmıştır. Elde edilen katsayıların Farkındalık alt boyutu için 0.88 , Beceri alt boyutu için 0.88 , Bilgi alt boyutu için 0.84 ve ölçeğin tamamı için 0.88 olduğu görülmüştür. Ölçeğin geçerlik çalışması için 332 psikolojik danışmana 62 maddeden oluşan bir form uygulanmıştır. Açımlayıcı ve Doğrulayıcı Faktör Analizi sonucu toplam varyansın \%50.86'sının açıklandığı ölçme aracında 26 madde ve üç boyut oluştuğu görülmüştür (Özer, 2014). Bu araştırmada ölçeğin güvenirlik çalışması için Cronbach Alfa katsayısı hesaplanmış ve elde edilen katsayının ölçeğin tamamı için 0.82 olduğu görülmüştür.

Kültürel Zekâ Ölçeği: Ang ve arkadaşları tarafından 2007 yılında geliştirilen ölçeğin Türk kültürüne uyarlaması İlhan ve Çetin (2014) tarafından yapılmıştır. Ölçek $5^{\prime} l i$ Likert tipindedir ve 20 maddeden oluşmaktadır. Ölçekten alınan yüksek puan kültürel zekânın da yüksek olduğu anlamına gelmektedir. Kültürel Zekâ Ölçeği'nde 4 alt boyut vardır. Bu alt boyutlar şunlardır: Davranış (maddeler: 16, 17, 18, 19, 20), Motivasyon (maddeler: 11, 12, 13, 14, 15), Biliş (maddeler: $5,6,7,8,9,10$ ) ve Üst biliş (maddeler: 1, 2, 3, 4). Türk kültürüne uyarlanan ölçeğin güvenirliği Cronbach Alfa katsayısı ile hesaplanmıştır. Katsayılar; Davranış alt boyutu için 0.71, Motivasyon alt boyutu için 0.75 , Biliş alt boyutu için .79 ve Üst biliş alt boyutu için 0.77 olarak hesaplanmıştır. Bu araştırmada Kültürel Zekâ Ölçeği'nin güvenirliği Cronbach Alfa katsayısı ile hesaplanmıştır. Bu analize göre güvenirlik katsayısının 0.88 olduğu belirlenmiştir.

Mesleki Deneyim ve Çok Kültürlü Psikolojik Danışma Eğitimi: Araştırmada yer alan Mesleki Deneyimdeğişkeni psikolojik danışmanların görev yaptıkları süreyiifade etmektedir. Lisans döneminin ardından aktif şekilde görev yapan psikolojik danışmanların deneyimleri görev yaptıkları yıl ile orantılı olarak kabul edilmiştir. Araştırmada yer alan katılımcıların mesleki deneyimleri 1 yıl ile 27 yıl arasında değişkenlikgöstermiştir. Çok Kültürlü Psikolojik Danışma Eğitimideğişkeni ise lisans veya lisansüstü dönemde Çok Kültürlü Danışma Eğimi ile ilgili alınan ders veya eğitimleri kapsar. Katılımcılar bu konuyla ilgili ders veya eğitim alanlar $(n=33)$ ve almayanlar $(n=80)$ olarak kategorize edilmiştir.

\section{Verilerin Analizi}

Araştırmada yer alan araştırma sorusu belirli bir kurama dayalı değildir. Araştırmada değişkenler arasındaki ilişkiyi değerlendirmek ve çoklu korelasyonun temel sorusuna yanıt vermek amaçlanmıştır. Bu tür araştırmalara en uygun analiz yöntemi ise standart çoklu regresyon analizidir (Tabachnick ve Fidell, 2015, s.143). Bu nedenle bu araştırmada standart çoklu regresyon analizi tercih edilmiştir.

Araştırma kapsamında toplanan verilerin normal dağılımını engelleyen ve mesleki deneyim süreleri 30 yılın üzerinde olan iki katılımcıya ait veriler analize alınmamıştır. Regresyon analizlerinde uç değerlerin bulunmaması oldukça önemlidir ve bu değerlerin gerekirse analizden çıkarılabileceği belirtilmektedir (Tabachnick ve Fidell, 2015, s.124). Araştırmada yer alan bağımlı ve bağımsız değişkenlerin normal dağılım sergilemesi gerekmektedir (Can, 2017, s.275). Normallik varsayımları incelenirken çoklu doğrusal regresyon analiz sayıltılarının karşılandığı görülmüştür. Bunlar: Skewness (Çarpıklık) ve Kurtosis (Basıklık) değerlerinin -1 ile +1 arasında olması, frekans dağılım grafiğinin (Histogram) simetrik bir çan şekline yakın olması, Q-Q Plot Grafiğindeki verilerin 45 derecelik bir açıya sahip bir doğruya yakın dağıması, eğiliminden ayrılmış Q-Q Grafiğindeki verilerin yatay sıfır çizgisi civarında rastgele dağılması ve Kutu-Çizgi Grafiğinde alt ve üst dikey çizgilerin boylarının birbirine yakın olması ve yatay çizginin kutuyu ortalamasıdır (Can, 2017).

Çoklu regresyon analizlerinde çoklu normalliğin sağlanması durumunda tüm değişkendeki verilerin normal dağıldığı varsayılır (Can, 2017). Bu araştırmada hem tüm değişkenlerin ayrı ayrı normalliğine bakılmış hem de çoklu normallik tabloları incelenmiştir. 
Normalliğin incelendiği tüm tablolarda tüm değişkenlere ilişkin verilerin normal dağılım sergilediği görülmüştür (Şekil 1).
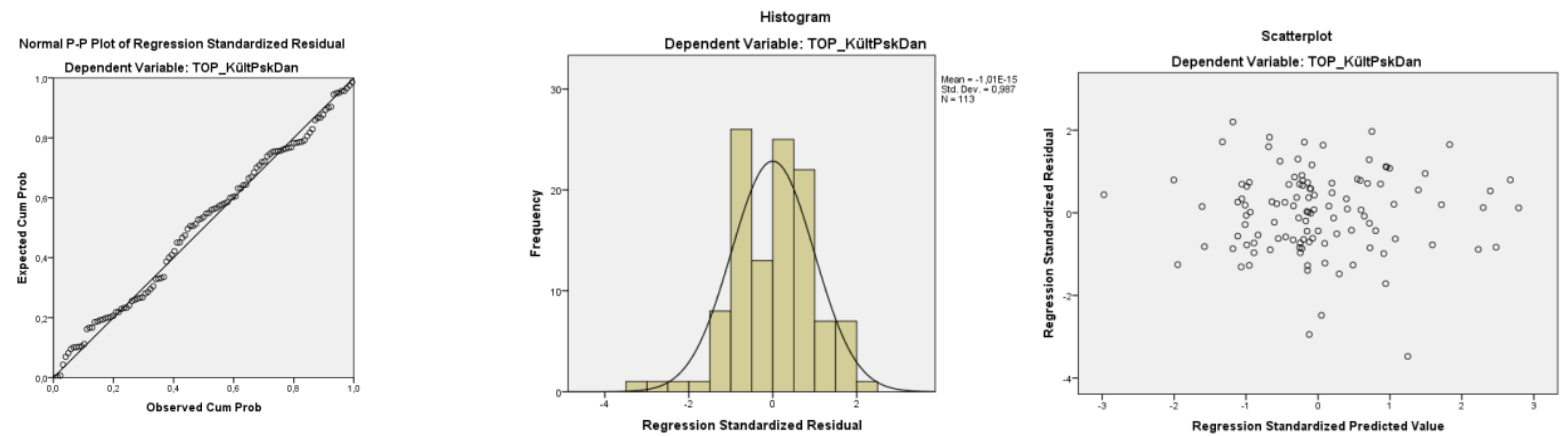

Şekil 1. Çoklu Doğrusal Regresyon Analizleri İçin Gerekli Çoklu Normalliğin Göstergeleri

Varyans Büyütme Faktörü (VIF) ve Tolerans değeri; bağımsız değişkenler arasında çoklu korelasyonun olup olmadığı hakkında bilgi vermektedir. Buna göre VIF değerinin 10'dan küçük; Tolerans değerinin ise $0,2^{\prime}$ den büyük olması gerekmektedir (Field, 2005). Bu araştırmada VIF ve Tolerans değerleri incelenmiş ve sorun oluşturabilecek çoklu korelasyonun olmadığı anlaşımıştır. VIF değerlerinin Kültürel Zekâ için 1.047, Mesleki deneyim için 1.023 ve Çok Kültürlü Eğitim için 1.031 olduğu görülmüştür. Tolerans değerlerinin ise Kültürel Zekâ için .956, Mesleki deneyim için .977 ve Çok Kültürlü Eğitim için .970 olduğu belirlenmiştir.

Regresyon modelini bozan uç değerlerin olup olmadığını incelemek amacıyla bir bağımsız değişkenin değişkenlerin ortalamasından ne derece farklılaştığını gösteren Mahalanobis değerleri hesaplanmıştır. Field (2005) örneklem sayısı 100, bağımsız değişken sayısının ise 3 civarı olduğu çoklu regresyon araştırmalarında ölçüt olarak alınacak Mahalanobis değerini 15 olarak kabul etmektedir. Bu araştırmada da en yüksek Mahalanobis değerinin 9.83418 olduğu görülmüştür. Dolayısıyla normallik varsayımının karşılanması amacıyla yapılan işlemlerde uç değerlerin olmadığı anlaşılmıştır.

\section{BULGULAR}

Bu bölümünde katılımcıların kültüre duyarlı psikolojik danışma yeterliklerine ilişkin Pearson Korelasyon, Nokta Çift Korelasyon ve Çoklu Doğrusal Regresyon analizleri yer almaktadır.

\section{1- Kültüre Duyarlı Psikolojik Danışma Yeterlikleri ile Kültürel Zekâ, Çok Kültürlü Psikolojik Danışma Eğitimi ve Mesleki Deneyim Arasındaki iliş̧ki}

Kültüre duyarlı psikolojik danışma yeterlikleri ile kültürel zekâ, çok kültürlü psikolojik danışma eğitimi ve mesleki deneyim arasındaki ilişkiler incelenmiş ve analiz sonuçlar Tablo 1'de sunulmuştur. 


\section{Tablo 1}

Kültüre Duyarlı Psikolojik Danışma Yeterlikleri ile Kültürel Zekâ, Çok Kültürlü Psikolojik Danışma Eğitimi ve Mesleki Deneyim Değişkenlerine Illişkin Korelasyonlar $(N=113)$

\begin{tabular}{lllll}
\hline & $\mathbf{1}$ & $\mathbf{2}$ & $\mathbf{3}$ & $\mathbf{4}$ \\
\hline 1. Kültüre Duyarlı Psikolojik Danışma Yeterlikleri & 1 & & \\
2. Kültürel Zekâ & $.57^{\star *}$ & 1 & \\
3. Mesleki Deneyim & $.21^{\star}$ & .13 & 1 \\
4. Çok Kültürlü Psikolojik Danışma Eğitimi & $-.18^{*}$ & -.16 & .05 & 1 \\
$\overline{\mathbf{x}}$ & 100.71 & 76.26 & 9 \\
Ss & 10.40 & 8.01 & 6.92 \\
\hline $\mathrm{N}=11{ }^{* *} \mathrm{p}<.01 \quad{ }^{*} \mathrm{p}<.05$ & & & \\
\hline
\end{tabular}

Çoklu regresyon araştırmalarında bağımlı değiş̧ken ile bağımsız değişkenler arasında anlamlı ilişkiler bulunmalıdır (Can, 2017, s.275). Ancak bu ilişkilerin .90 düzeyinde olmaması ve dolayısıyla çoklu bağlantılılık sorunu bulunmaması gerekmektedir (Çokluk, Şekercioğlu ve Büyüköztürk, 2018, s.35). Bu ilişkileri görmek amacıyla bağımlı değişkenler ile bağımsız değişkenler arasındaki korelasyon ilişkisi incelenmiştir. Araştırmada yer alan "Çok Kültürlü Psikolojik Danışma Eğitimi Alma" değişkeni kategorik bir değişken olduğundan bağımlı değişken ile arasındaki ilişki "Nokta Çift Serili Korelasyon" analizi ile hesaplanmıştır. Yordanan değişkenin yordayıcı değişkenler ile arasında anlamlı ilişkiler olduğu görülmüştür $(p<.05)$. Kültüreduyarlı psikolojik danışma yeterlikleri ile kültürel zekâ arasındaki korelasyon $r=.57$, mesleki deneyim arasındaki korelasyon $r=.21$ ve çok kültürlü psikolojik danışma eğitimi arasındaki korelasyon $r=$ -.18 olarak hesaplanmış ve çoklu bağlantılııı sorunu olmadığı anlaşılmışır.

\section{2- Kültüre Duyarlı Psikolojik Danışma Yeterliğinin Yordanmasında Kültürel Zekâ, Çok Kültürlü Psikolojik Danışma Eğitimi ve Mesleki Deneyimin Rolüne illişkin Regresyon Analizi}

Kültüre duyarlı psikolojik danışma yeterliğinin yordanmasında kültürel zekâ, mesleki deneyim ve çok kültürlü psikolojik danışma eğitiminin rolüne ilişkin çoklu doğrusal regresyon analizi yapılmış ve analiz sonuçları Tablo 2'de yer almıştır.

\section{Tablo 2}

Kültürel Zekâ, Çok Kültürlü Psikolojik Danışma Eğitimi ve Mesleki Deneyim Değişkenlerinin Kültüre Duyarlı Psikolojik Danışma Yeterliğini Yordamasına ilişkin Çoklu Doğrusal Regresyon Analizi Sonuçları (N=113)

\begin{tabular}{|c|c|c|c|c|c|c|c|}
\hline Değişken & B & $\begin{array}{l}\text { Standart } \\
\text { Hata }\end{array}$ & $\beta$ & $\mathbf{t}$ & $\mathbf{p}$ & İkili r & Kısmi r \\
\hline (Sabit) & 46.363 & 7.874 & - & 5.888 & .000 & - & - \\
\hline Kültürel Zekâ & .699 & .102 & .538 & 6.836 & .000 & .572 & .548 \\
\hline Mesleki Deneyim & .211 & .117 & .141 & 1.807 & .074 & .206 & .170 \\
\hline $\begin{array}{l}\text { Çok Kültürlü Psikolojik } \\
\text { Danışma Eğitimi }\end{array}$ & -.978 & .759 & .101 & -1.288 & .200 & .179 & -.122 \\
\hline$R=.596$ & & $\mathrm{R}^{2}=0.337$ & & & & & \\
\hline$\left(F_{(3-109)}=19.984\right.$ & & $p=0.00$ & & & & & \\
\hline
\end{tabular}

Psikolojik danışmanların kültüre duyarlı psikolojik danışma yeterliklerini yordamada kültürel zekâ, mesleki deneyim ve çok kültürlü psikolojik danışma eğitimi değişkenlerinin rolünün incelendiği bu araştırmada çoklu doğrusal regresyon analizi yapılmıştır. Analiz sonuçlarına göre kültürel zekâ, mesleki deneyim ve çok kültürlü psikolojik danışma eğitimi değişkenleri birlikte, kültüre duyarlı psikolojik danışma yeterlikleri ile anlamlı bir ilişkiye $(R=.596$, $\left.\mathrm{R}^{2}=.337\right)$ sahiptir $\left(\mathrm{F}_{(3-109)}=19.984, \mathrm{p}<.05\right)$. 
Araştırmada bulunan yordayıcı değişkenlerin kültüre duyarlı psikolojik danışma yeterlikleri değişkenindeki değişimin \%34'ünü açıkladığı görülmüştür. Standartlaştııılmış regresyon katsayıları incelendiğinde yordanan değişken üzerinde yordayıcı değişkenlerin göreli önem sıralaması Kültürel Zekâ( $\beta=.538)$, Mesleki Deneyim $(\beta=.141)$ ve Çok Kültürlü Psikolojik Danışma Eğitimi ( $\beta=-$.101) şeklindedir. Kültürel Zekâ, Mesleki Deneyim ve Çok Kültürlü Psikolojik Danışma Eğitimi değişkenleri birlikte, Kültüre Duyarlı Psikolojik Danışma Yeterliklerini anlamlı şekilde yordamaktadır. Regresyon katsayılarının anlamlıık testleri incelendiğinde ise yordayıcı değişkenlerden yalnızca Kültürel Zekânın $(p<.00)$ tek başına Kültüre Duyarlı Psikolojik Danışma Yeterliği değişkenini yordadığı görülmüştür.

Regresyon analizlerinde etki büyüklüğünün bulunması için $\mathrm{f}^{2}$ değeri (standartlaştırılmış etki büyüklüğü) hesaplanmalıdır. $f^{2}$ değerinin hesaplanmasında ise $f^{2}=R^{2} /\left(1-R^{2}\right)$ formülü kullanılmaktadır. Etki büyüklüğünün sınıflandırılması $f^{2}$ değerine göre şu şekilde oluşturulmuştur: $.02 \leq \mathrm{f}^{2}<.15$ düşük etki; $.15 \leq \mathrm{f}^{2}<.35$ orta etki; $.35 \leq \mathrm{f}^{2}$ geniş etki (Cohen, 1988). Bu araştırmada ise etki büyüklüğü $f^{2}=R^{2} /\left(1-R^{2}\right)$ formülüyle hesaplanmış ve $f^{2}=(.355) /(1-.355)=.55$ olarak bulunmuştur. Bu etki büyüklüğünün ise geniş düzeyde olduğu görülmüştür.

\section{TARTIŞMA, SONUÇ VE ÖNERILER}

Araştırma sonuçlarına göre psikolojik danışmanların kültüre duyarlı danışma yeterliklerine sahip olmalarının önemli bir beceri olduğu görülmektedir. Kültüre duyarlı danışma yeterlik düzeyi yüksek olan danışmanların temel psikolojik danışmanlık becerileri daha yüksektir (Korban, 2018). Barden ve Greene (2015) de çok kültürlü danışma yeterliğine sahip olan danışmanların daha etkili ve verimli danışma hizmeti verebileceğini ifade etmiştir. Danışma sürecinde kültüre duyarlıığın önemine değinen Ratts ve Greenleaf'e (2017) göre okul ortamında farklı kültürlerdeki öğrencilerin eşit haklara sahip olabilmeleri için okul psikolojik danışmanların çok kültürlü danışma yeterliğine sahip olmaları gerekmektedir. Bu durum özellikle farklı kültürlerdeki öğrencilerin yaşadığı bölgelerdeki okullar için önemlidir. Dillon ve arkadaşları (2016) psikolojik danışmanların çok kültürlü danışma yeterliklerini danışan ve danışmanların bakış açılarıyla incelemiştir. 133 danışan ve 24 danışman üzerinde yapılan araştırmaya göre psikolojik danışmanını kültüre duyarlı danışma konusunda yetkin gören danışanların terapi süreci sonunda kendini daha iyi hissettiği görülmüştür.

Bu araştırmada psikolojik danışmanların kültüre duyarlı psikolojik danışma yeterlikleri ile kültürel zekâ, çok kültürlü psikolojik danışma eğitimi ve mesleki deneyimleri arasında anlamlı ilişkilerin olduğu görülmüştür. Ayrıca kültürel zekânın kültüre duyarlı psikolojik danışma yeterliğini anlamlı şekilde yordadığı tespit edilmiştir. Genç (2019) de benzer şekilde psikolojik danışmanların kültürel zekâlarının kültüre duyarlı danışma yeterliklerini yordadığını ortaya koymuştur. Kültüre duyarlı psikolojik danışma yeterlikleri ile kültürel zekâ arasındaki ilişkiyi ortaya çıkaran bir diğer araştırma Leong ve Lee (2016) tarafından yapılmıştır. Buna göre bilişsel kültürel zekâ stratejilerini kullanan danışmanların kültüre duyarlı danışma yeterliklerinin daha yüksek olduğu anlaşılmıştır.

Çok kültürlü psikolojik danışma eğitimi alan psikolojik danışmanların danışma yeterliklerini daha yüksek bulan Bakioğlu'nun (2017) araştırma sonuçları bu araştırma sonuçlarıyla tutarlılık göstermektedir. Araştırmasında benzer bir sonucuna ulaşan Tourek (2014) de eğitim yaşamında çok kültürlü psikolojik danışma ile ilgili ders alan psikolojik danışmanların kültüre duyarlı danışma yeterliklerini daha yüksek bulmuştur. Bu araştırmadan farklı bir sonuç ortaya koyan Demir (2016) 460 okul psikolojik danışmanı üzerinde yaptığı araştırmada çok kültürlü psikolojik danışma eğitiminin psikolojik danışmanların kültüre duyarlı danışma yeterliklerini değiştirmediği sonucuna ulaşmıştır. 
Bu araştırmada kültüre duyarlı psikolojik danışma yeterlikleri üzerinde mesleki deneyimin tek başına yordayıcı bir rolü olmadığı görülse de aralarında anlamlı bir ilişki olduğu saptanmıştır. Mesleki deneyimi farklı psikolojik danışmanların kültüre duyarlı danışma yeterliklerini inceleyen Crook'a (2010) göre mesleki deneyimi fazla olan danışmanlar çok kültürlü danışma yeterliklerini daha yüksek algılamaktadır. Farklı sonuçlara ulaşan Güçlücan (2016) ve Genç (2019) psikolojik danışmanların mesleki deneyimlerine göre kültüre duyarlı danışma yeterliklerinin değişmediğini ifade etmiştir. Bunun nedeni psikolojik danışmanların kendi kültürlerine yakın yerlerde görev yapmayı tercih etmeleri olabilir (Demir, 2016).

Araştırmanın sonuçları doğrultusunda bazı öneriler aşağıda sunulmuştur:

- Psikolojik Danışmanlık ve Rehberlik bölümünün lisans ve lisansüstü programlarında Kültüre Duyarlı Psikolojik Danışma dersinin zorunlu ders olması sağlanabilir.

- Lisans ve lisansüstü programlarda psikolojik danışma uygulaması derslerinde öğrenciler farklı kültürlerdeki danışanlarla danışma yapmaları konusunda süpervizörleri tarafından yönlendirilebilir.

- Deneyim ile kültüre duyarlı psikolojik danışma yeterliği arasındaki ilişki dikkate alındığında; psikolojik danışman adayları için psikolojik danışma uygulamaları dersinin kapsamının genişletilmesi ve danışma uygulamalarının arttırılması önemli görülmektedir.

- Kültürel zekânın kültüre duyarlı psikolojik danışma yeterliğini yordadığı göz önüne alındığında; psikolojik danışmanların kültürel zekâlarını geliştirmeye yönelik eğitim programları verilebilir ve bu konuda müdahale edici deneysel araştırmalar yapılabilir.

- Rehberlik Araştırma Merkezleri tarafından okul psikolojik danışmanlarına yönelik kültüre duyarlı danışma yeterliğini arttırmak amacıyla hizmetiçi eğitimler düzenlenebilir.

- Psikolojik danışmanların kültüre duyarlı danışma yeterliğini etkileyen nedenler hakkında daha ayrıntılı analizlerin yapılabileceği nitel araştırmalar literatüre katkı sağlayacaktır.

\section{KAYNAKLAR}

Aydın, B. (2014). Kültüre duyarlı psikolojik danışma eğitiminin psikolojik danışman adaylarının kültürel duyarlılı düzeyleri üzerindeki Etkisi. Yayınlanmamış Doktora Tezi, Karadeniz Teknik Üniversitesi Eğitim Bilimleri Enstitüsü, Trabzon.

Bakioğlu, F. (2017). Psikolojik danışman adaylarının özyeterlikleri ile kültüre duyarlılıları, cinsiyet rolleri ve bilinçli farkındalıkları arasındaki ilişkilerin incelenmesi. Yayınlanmamış Doktora Tezi, Anadolu Üniversitesi Eğitim Bilimleri Enstitüsü, Eskişehir.

Barden, S. M.,\& Greene, J. H. (2015). An investigation of multicultural counseling competence and multicultural counseling self-efficacy for counselors-in-training. International Journal for the Advancement of Counselling, 37(1), 41-53.

Bektaş, Y. (2006). Kültüre duyarlı psikolojik danışma yeterlikleri ve psikolojik danışman eğitimindeki yeri. Ege Eğitim Dergisi, 7 (1), 43-59.

Can, A. (2017). SPSS ile Bilimsel Araştırma Sürecinde Nicel Veri Analizi. (5. Baskı). Ankara: Pegem A Yayıncılık. Charkuff, R. (2011). 21. Yüzyılda Yardım Etme Sanatı. Ankara: Nobel Yayınevi Basım Dağıtım.

Cohen, J. (1988). Statistical Power Analysis for the Behavioral Sciences (2nd Ed.). Hillsdale, NJ: Lawrence Earlbaum Associates.

Corey, G. (2008). Psikolojik Danışma Kuram ve Uygulamaları. Ankara: Mentis Yayıncılık.

Crook, T. (2010). Relationship between counseling self-efficacy and multicultural counseling self-efficacy among school counselors. Doctoral Thesis, Auburn University, Alabama.

Çelik, H. (2008). Çokkültürlülük ve Türkiye'deki görünümü. Uludağ Üniversitesi Fen-Edebiyat Fakültesi Sosyal Bilimler Dergisi, 9(15), 319-332.

Çokluk, Ö., Şekercioğlu, G., \& Büyüköztürk, Ş. (2018). Sosyal Bilimler lç̧in Çok Değişkenli i̇statistik SPSS ve LISREL Uygulamaları. Ankara: Pegem Akademi.

Davis, D. N. (2014). Complexity over looked: enhancing cultural competency in the white lesbian counseling trainee through education and supervision.Journal of Lesbian Studies. 18 (2), 192-201. 
Demir, H.i. (2016). Okul psikolojik danışmanlarının kültüre duyarlı psikolojik danışma yeterlikleri ve çok kültürlü kişilik özelliklerinin incelenmesi. Yayınlanmamış Yüksek Lisans Tezi, Yüzüncü Yıl Üniversitesi Eğitim Bilimleri Enstitüsü, Van.

Dillon, F. R., Odera, L., Fons-Scheyd, A., Sheu, H. B., Ebersole, R. C., \& Spanierman, L. B. (2016). A dyadic study of multicultural counseling competence. Journal of Counseling Psychology, 63(1), 57-66.

Earley, P. C.,\& Ang. S. (2003). Cultural Intelligence: Individual Interactions Across Cultures. California: Stanford University Pres.

Erdur-Baker, Ö. (2007). Psikolojik danışma ve kültürel faktörler. Türk Psikolojik Danışma ve Rehberlik Dergisi. 3 (27), 109-122.

Field, A. (2005). Discovering Statistics Using SPSS. London: Sage Publication.

Genç, A. (2019). Psikolojik danışmanların psikolojik danışman nitelikleri ile kültüre duyarlı psikolojik danışma yeterlikleri arasındaki ilişkide kültürel zekânın ve bilişsel esnekliğin aracı rolü. Yayınlanmamış Doktora Tezi, Yıldız Teknik Üniversitesi Sosyal Bilimleri Enstitüsü, İstanbul.

Güçlücan, N. (2016). Psikolojik danışmanların kültürel duyarlılı algılarının demografik ve mesleki değişkenler açısından incelenmesi. Yayınlanmamış Doktora Tezi, Anadolu Üniversitesi Eğitim Bilimleri Enstitüsü, Eskişehir.

Johnson, B., \& Christensen, L. (2014). Eğitim araştırmaları nicel, nitel ve karma yaklaşımlar. (4. Baskı). Ankara: Eğiten Kitap.

Kağnıcı, Y. D. (2013). Çok kültürlü psikolojik danışma eğitiminin rehberlik ve psikolojik danışmanlık lisans programlarına yerleştirilmesi. Türk Psikolojik Danışma ve Rehberlik Dergisi, 5 (40), 222-231.

Korban, i. (2018). Psikolojik danışmanların çok kültürlü psikolojik danışma yeterliklerinin psikolojik danışma becerilerini yordama düzeyi. Yayınlanmamış Yüksek Lisans Tezi, Sabahattin Zaim Üniversitesi Sosyal Bilimleri Enstitüsü, İstanbul.

Korkut-Owen, F., Tuzgöl-Dost, M., \& Bugay, A. (2014). Psikolojik danışman eğitimcilerinin psikolojik danışman adaylarının mesleğe ilişkin kişisel eğilimleri hakkındaki görüşleri. International Journal of Human Science. 11.

Leong, F. T.,\& Lee, S. H. (2006). A cultural accommodation model for cross-cultural psychotherapy: Illustrated with the case of Asian Americans. Psychotherapy:Theory, Research, Practice, Training, 43(4), 410-423.

Özer, Ö. (2014). Çokkültürlü Psikolojik Danışma Yeterlikleri Ölçeğinin Geliştirilmesi. Yayınlanmamış Yüksek Lisans Tezi. Gaziosmanpaşa Üniversitesi Eğitim Bilimleri Enstitüsü, Tokat.

Ratts, M. J.,\& Greenleaf, A. T. (2017). Multicultural and social justice counseling competencies: A leadership framework for professional school counselors. Professional School Counseling, 21(1b), 1-9.

Sue, D.W. (2001). Multidimensional facets of cultural competence. The Counseling Psychologist, 29 (6), 790821.

Tabachnick, B.G. \& Fidell, L.S. (2015). Çok Değişkenli Istatistiklerin Kullanımı. Ankara: Nobel Akademik Yayıncılık.

Tourek, S. C. (2014). A case for mindfulness practice in fostering multicultural competence in counseling. Doctoral Thesis, University Of Minnesota, St. Paul.

Whitman, J. S., \& Bidell M, P. (2014). Affirmative lesbian, gay, and bisexual counselor education and religious beliefs: How do webridge the gap? Journal of Counseling and Development. 922, 162-169.

Yakışır, A.N. (2009). Modern bir olgu olarak çokkültürlülük. Yayınlanmamış Yüksek Lisans Tezi, Selçuk Üniversitesi Sosyal Bilimler Enstitüsü, Konya.

Yüksel-Şahin, F. (2018). Psikolojik Danışmanlar Için El Kitabı. Ankara: Nobel Yayınevi Basım Dağıtım. 


\title{
Predicting Multicultural Counseling Competencies: The Role of Cultural Intelligence, Multicultural Counseling Education and Professional Experience
}

\author{
Oğuzhan Yıldırım (PhD Student) \\ Ondokuz Mayıs University-Turkey \\ oguzhanyildirim.pdr@gmail.com
}

\begin{abstract}
The purpose of this study was to examine the prediction level of psychological counselors' cultural intelligence, multicultural counseling education and professional experiences on the theirs' multicultural counseling competencies. The study carried out in the screening model was conducted with active 115 psychological counselors. "Multicultural Counseling Competencies Scale" and "Cultural Intelligence Scale" were used to collect data in the study. Multiple linear regression analysis and Pearson correlation analysis were used in the analysis of the obtained data. According to the results of the research, it was found that multicultural counseling competencies and cultural intelligence, multicultural counseling education, professional experience were significantly related. It was found that the predictor variables together accounted for $34 \%$ the variance. According to the significance tests of the regression coefficients, it was determined that only cultural intelligence predicted multicultural counseling competencies.
\end{abstract}

Keywords:Multicultural counseling competencies, cultural intelligence, multicultural counseling education, professional experience

\section{Suggested Citation:}

Yıldırım, O. (2020). Predicting Multicultural Counseling Competencies: The Role of Cultural Intelligence, Multicultural Counseling Education and Professional Experience. E-International Journal of Educational Research, Vol: 11, No: 1, 2020, pp. 41-52, DOI: 10.19160/ijer.676897

\section{EXTENDED ABSTRACT}


Introduction: Psychological counseling is a mental health profession that helps people to be selfsufficient in their personal, social, career and academic life and supports them to solve their problems (Yüksel-Şahin, 2018). Psychological counselors need to have certain features in order to develop their competencies. The counselors have self-awareness, innovative thinking, self-esteem, authentic and honest features, accepting mistakes, humor and they should be aware of the impact of culture in the counseling process (Corey, 2008). The two most important components of the counseling process are the counselor and the client. Psychological counselors can transfer the cultural features to the counseling process. So they should be aware and careful that their cultural features affect the therapy process (Corey, 2008). Culture does not only contain phenomena such as race and ethnicity. Many concepts related to culture are considered in the process of multicultural counseling. Gender (Sue, 2001), sexual orientation (Davis, 2014), religious belief (Whitman \& Bidell, 2014) and socioeconomic status (Corey, 2008) are included in multicultural counseling.

People living together cannot be expected to be the same and have common features. Even people living in the same society have different features in terms of personality characteristics, lifestyles, family life and economic conditions. According to Bektaş (2006), one of the biggest reasons for the differences among people is culture. These differences can also cause some problems.Therefore, psychological counselors should have multicultural psychological counseling competencies in order to provide efficient and effective counseling services (Demir, 2016).

Cultural intelligence is the ability that adapt to different cultures, to communicate with people in these cultures and to exhibit behaviors compatible with the culture (Early \& Ang, 2003). Cultural intelligence first emerged in the USA and its importance was understood in the 1960s. One of the most important issues in multicultural counseling is psychological counselor education (Kağnıcl, 2013). It is important that psychological counseling education include multicultural counseling skills (Aydın, 2014). It is thought that more experienced psychological counselors had more counseling processes and worked more with clients from different cultures. When all these are taken into consideration, it is seen that it is important to investigate multicultural psychological counseling competencies with cultural intelligence, multicultural counseling education and professional experience. The purpose of this study was to examine the predictive role of psychological counselors' cultural intelligence, multicultural counseling education and professional experiences on the their multicultural counseling competencies.

Method: The study carried out in the screening model was conducted with active 115 psychological counselors (65 women, 48 men) working in kindergarten, primary school, middle school and high school and in Turkey's seven geographical regions. The participants were selected by simple random sampling method. "Multicultural Counseling Competencies Scale" and "Cultural Intelligence Scale" were used to collect data in the study. Multiple linear regression analysis and Pearson correlation analysis were used in the analysis of the obtained data.

Findings: According to the results of the research, it was found that multicultural counseling competencies and cultural intelligence, multicultural counseling education, professional experience were significantly related. The correlation coefficients between multicultural psychological counseling competencies and cultural intelligence was $r=.57$, between multicultural psychological counseling competencies and professional experience was $r=.21$ and between multicultural psychological counseling competencies and multicultural counseling education was $r=-.18$.

It was found that the predictor variables together accounted for $34 \%$ the variance. The relative importance of the predictor variables was $(\beta=.538)$ for cultural intelligence, $(\beta=.141)$ for professional experience, and ( $\beta=-$. 101) for multicultural counseling. According to the significance tests of the regression coefficients, it was determined that only cultural intelligence predicted multicultural counseling competencies. In this study, the effect size was calculated as f2 = (.355) / $(1-355)=.55$. The effect size was found to be large. 
Results and Discussion: According to the results of the research, it is seen that counselors with multicultural counseling competencies are more skilled in basic psychological counseling (Korban, 2018). Barden and Greene (2015) also stated that counselors with multicultural counseling competencies can provide more effective and efficient counseling service. According to Ratts and Greenleaf (2017), school counselors must have the multicultural counseling competencies to ensure equal rights for students with different cultures. In this study, it was seen that there were significant relationships between multicultural counseling competencies, cultural intelligence, professional experience and multicultural counseling education. In addition, it was found that cultural intelligence significantly predicted the multicultural psychological counseling competencies. Genç (2019) similarly stated that the cultural intelligence of psychological counselors predicted their multicultural counseling competencies. The counselors using cognitive cultural intelligence strategies have high level of multicultural counseling competencies (Leong \& Lee, 2016). According to this research, Bakioğlu (2017) and Tourek (2014) found that counselors receiving multicultural counseling education have high level of multicultural counseling competencies. In this study, it was found that there was a significant relationship between multicultural psychological counseling competencies and professional experience. According to Crook (2010), the counselors with more professional experience perceive themselves as more competencies in multicultural counseling. However, Güçlücan (2016) and Genç (2019) stated that the professional experiences of psychological counselors doesn't affect their multicultural counseling competencies. 